\title{
Pedagogical Affect, Student Interest and Learning Performance
}

\author{
José Luís Abrantes*, Cláudia Seabra and Luís Filipe Lages
}

This research was funded by a research grant from NOVA EGIDE to Luís Filipe Lages. The authors acknowledge two anonymous JBR reviewers for their feedback on an early version of the article.

José Luís Abrantes is a Visiting Scholar at Universidade Nova de Lisboa, Faculdade de Economia, and Professor of Marketing at Instituto Politécnico de Viseu, Escola Superior de Tecnologia, Campus Politécnico de Viseu, 3504-510 Viseu, Portugal. Phone: ++ 351.232.480590, Fax: ++351.232.424651, e-mail: jlabrantes@dgest.estv.ipv.pt* (corresponding author)

Cláudia Seabra is Assistant Professor of Marketing and Tourism at Instituto Politécnico de Viseu, Escola Superior de Tecnologia, Campus Politécnico de Viseu, 3504-510 Viseu, Portugal. Phone: ++ 351.232.480598, Fax: ++351.232.424651, e-mail: cseabra@ dgest.estv.ipv.pt

Luís Filipe Lages is a Visiting Scholar at London Business School and Assistant Professor of Marketing and International Business at Universidade Nova de Lisboa, Faculdade de Economia, Campus de Campolide, 1099-032 Lisboa, Portugal. Phone: ++ 351.21.3801.600, Fax: ++ 351.21.3886.073, e-mail: lflages@fe.unl.pt, url: http://prof.fe.unl.pt/ lflages 


\title{
Pedagogical Affect, Student Interest and Learning Performance
}

\begin{abstract}
Using a sample of over 1000 students, this study reveals that student perceived learning depends directly on their interest and behavior (pedagogical affect and learning performance), and indirectly on student/instructor interaction, responsiveness, organization, liking/concern and learning performance. Student interest is indirectly affected by liking/concern through its influence on learning performance. Recommendations for schools, department heads and university administrators are addressed. Directions for future research are also presented.
\end{abstract}

Subject Areas: Pedagogy, Student Behavior, Learning Outcomes, Marketing Education.

\section{INTRODUCTION}

Educators play a major role in the formation of students' personal identities by stimulating their development into active elements of society (Willemse, Lunenberg and Korthagen, 2005). Through education they are expected to transmit knowledge to learners. Teachers and students should be jointly involved and dedicated to the learning process and school's objectives. Schools with a clear vision of teaching and learning goals can make their actions more productive (Silins and Mulford, 2004).

Issues related to perceived learning (e.g. student evaluation of instructors, course organization and student interest) have received recent attention from researchers (e.g., Engelland, Workman and Singh, 2000; Paswan and Young, 2002; Young, Klemz and Murphy, 2003). However, due to innumerable measurement difficulties, it has not been possible to find consensus on key determinants of teaching effectiveness and students' learning (Marks, 2000). The lack of a solid theory in the field together with a diversity of measures impacts on the reliability of existing findings, as researchers question if existing findings are a consequence of independent variables or a consequence of the flaw operationalization. It is our goal to develop a solid measurement instrument that builds on existing theory in the field to measure key intangible educational concepts for an enhanced identification of key determinants of student perceived learning. 
We start by presenting an overview of the current literature. Second, the conceptual framework and the hypotheses are developed. This is followed by the research methodology. The conceptual framework is then empirically tested using confirmatory factor analysis and structural equation modeling with data from 1095 students. Implications for theory and school's managerial practice, research limitations and future directions are also considered.

\section{CONCEPTUAL MODEL}

While building on previous research, our conceptual model (see Figure 1) presents major determinants of perceived learning.

Insert Fig.1 about here

Student-teacher interaction refers to the opportunity to ask questions, to express one's ideas freely and have an open discussion in class. Non-threatening interaction allows students to ask questions, practice free expression of ideas, develop their own skills and improve class discussion (Paswan and Young, 2002). This has been pointed as the most frequently recognized teaching and learning method for both educators and pupils (Willemse, Lunenberg and Korthagen, 2005), as it has a positive influence on student ratings of instruction (Paswan and Young, 2002). A stronger student-instructor interaction also has a major impact on instructor involvement, as the latter will invest more in her/his students. Students are attentive and know when instructors are investing in them, and will recognize those efforts (Paswan and Young, 2002). Hence, we consider that student-instructor interaction will influence students' perception of instructors' pedagogical affect. Therefore,

\section{H1: A higher degree of student-instructor interaction will lead to a higher level of pedagogical affect.}

Responsiveness is a well-established concept in the services context (Parasuraman, Zeithaml and Berry, 1985). In the education area, responsiveness is considered to be the willingness to help students by providing a prompt service. There is a strong relationship between instructor involvement and student interest (Paswan and Young, 2002). Teachers must have the capacity to know students' needs and be quick in responding to them. Responsive teaching implies a capacity to engage systematic learning from the teaching 
context and practice as well as from a more generalized teaching theory (Hammond and Snyder, 2000). Students are demanding consumers who want a good and prompt service and know when instructors are involved. When this occurs, students respond in kind (Paswan and Young, 2002). Hence,

\section{H2: A higher degree of instructor responsiveness will lead to a higher level of student interest.}

Organization represents the course structure and refers to the systematic relation between concepts and course direction (Marks, 2000). Educators' organization, clarity and comprehensiveness are important in the student learning process (Feldman, 1988). Course organization is directly related with students' ability to handle uncertainty. An unstructured course would make students feel uncomfortable and consequently have a negative impact on the evaluation of the instructor and themselves (Marsh, 1987, 1991). Conversely, a more structured and organized course may lead to a favorable instructor assessment and selfevaluation (Marks, 2000; Marsh, 1991). Consequently, organization has a positive path to learning and instructor evaluation. So, we consider the following hypothesis:

\section{H3: A higher degree of course organization will lead to a higher-level pedagogical affect.}

Liking/concern refers to the teacher's emotional qualities, namely caring disposition.

Students evaluate their instructors beyond their objective teaching and scientific abilities. The duration and nature of relationships between students and teachers influence the processes and outcomes of teaching (Hammond and Snyder, 2000). Teachers should not only be transmitters of knowledge and skills, but also take care of their relationships with students. Often students want to know if instructors are likeable more than if they are knowledgeable. In many situations, students are more interested in finding out if lectures proposed are entertaining, rather than if the content is accurate and up to date (Cahn, 1987). Teaching style allied to personal attractiveness has been demonstrated to enhance learning. When a degree of entertainment is combined with other aspects of quality teaching, it is likely that entertainment will promote student involvement and consequently student learning (Marks, 2000). Therefore:

\section{H4: A higher level of instructor liking/concern will lead to a higher level of learning performance.}

Learning performance assesses multiple dimensions of learning outcomes, such as students' self-evaluation of knowledge, understanding, skills, and desire to learn more 
(Young, Klemz and Murphy, 2003). It is commonly associated with a more positive attitude towards the environment, namely courses and teachers (Duke, 2002; Dunn et al., 1990). If students incur positive attitudes towards learning achievements, teachers will be more willing to commit themselves to their students (Paswan and Young, 2002) and, simultaneously, students will evaluate teachers' methods in a more positive way. Hence, we hypothesize the following:

\section{H5: A higher degree of student learning performance will lead to a higher level of student's pedagogical affect.}

Motivation variables are also correlated with learning outcomes. It is students' perception of course outcome (e.g. an intellectually challenging course) that helps him/her to become more competent (Paswan and Young, 2002) and more interested. When students perceive that their learning performance is relevant, there is an expected increased interest in the course. Hence, we propose the following:

\section{H6: A higher degree of student learning performance will lead to a higher-level student interest.}

Learning performance was found to be associated with perceived learning (Marks, 2000). Education level increases as students pass through various stages of learning: comprehension, application, analysis, synthesis and evaluation. These stages help researchers to evaluate the extent to which learning outcomes are attained (Duke, 2002). Hence, since overall course evaluation is a function of learning performance and instructor evaluation (Gremler and McCollough, 2002), we propose:

\section{H7: Higher learning performance will lead to higher perceived learning.}

Student interest reflects his/her input into the course, such as attention to the class, interest in learning material, perception of the course's intellectual challenge, and acquired competence in the field. Students' interest facilitates effective teaching and creates a more favorable learning environment (Marsh and Cooper, 1981). Students reject a learning environment that runs contrary to their preferences (Hsu, 1999). When learners are more interested, they will perceive to have learned more (Tynjälä, 1999) and this will reflect students overall evaluation about their learning process. Hence:

\section{H8: Higher student interest will lead to higher perceived learning.}

The teacher plays a major influence in molding student values, especially through his/her instructional approaches (Willemse, Lunenberg and Korthagen, 2005). Pedagogical affect refers to the student's positive thoughts or feelings toward the instructional methods used in class. Students tend to prefer instructional 
methods that are more experiential and class-interactive (Frontczak, 1998; Matthews, 1994) that encourage understanding, emphasize application and integrate theoretical and practical knowledge, and produce more transferable knowledge (Tynjälä, 1999; Frontczak, 1998; Karns, 1993). Educators are expected to understand the learning process in order to design and implement teaching methods aligned with students' needs that enhance learning (Hsu, 1999). When teachers use instructional methods that are in line with students' preferred learning styles, learners will develop favorable attitudes towards the teacher's pedagogical attributes. This is normally presented as pedagogical affect (Richard, Misra and Auken, 2000). A positive attitude toward teaching style leads to higher achievement and learning performance (Dunn et al., 1990; Paswan and Young, 2002; Young, Klemz and Murphy, 2003). Hence:

\section{H9: A higher degree of student's pedagogical affect will lead to higher perceived learning.}

\section{METHOD}

\section{Survey instrument and data collection}

An initial version of the instrument was developed while incorporating measures used in past research. These measures were then discussed with people capable of understanding the nature of the concept being measured. Following revisions, we used a pre-test sample of 30 students in order to test the reliability of the factors through Cronbach alpha. The pre-test results were used to further refine the questionnaire. Final questionnaires were then delivered to the students by teachers of ten different Portuguese schools. See Appendix A for a list of construct, items, reliabilities and their sources. The data were collected in-class at the end of 2004. Students were from ten different schools for a total of 1095. In the largest school we had 173 answers, while in the smallest 14. The average mean of respondents by school was 110. Of the total number of respondents, $47.5 \%$ were male and $52.5 \%$ were female.

\section{FINDINGS}

In order to assess the validity of the measures, the items were subjected to a confirmatory factor analysis, using full-information maximum likelihood (FIML) estimation procedures in LISREL 8.54. Although the chi-square for this model is significant $\left(X^{2}=1104.16,322 d f, \mathrm{p}<.00\right)$, the fit indices reveal a good model. The CFI, IFI, TLI, RMSEA of this measurement model are $.99, .99, .98$, and .047 respectively. Convergent validity is evidenced by the large and significant standardized loadings of each item on its intended construct (average loading size was 0.76 ). Discriminant validity among the constructs was 
assessed using the Fornell and Larcker (1981) test; all possible pairs of constructs passed this test (see Table 1 and Appendix A).

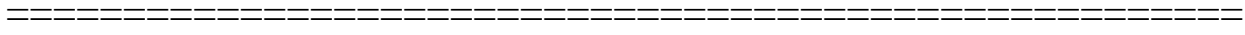

Insert Table 1 about here

The final structural model has a chi-square of 1323.24 (335 df, $\mathrm{p}<.00$ ); the fit indices suggest a good fit of the model to the data $(\mathrm{CFI}=0.98, \mathrm{IFI}=0.98, \mathrm{TLI}=.98, \mathrm{RMSEA}=0.052)$. The estimation results for the structural paths are exhibited in Figure 2. As it is possible to observe in Figure 2, all the 9 hypotheses have been confirmed.

Insert Figure 2 about here

Findings reveal that perceived learning is influenced primarily by students' interest, and then by pedagogical affect and learning performance. As proposed in earlier research (Marks, 2000; Young, Klemz and Murphy, 2003), students will learn more when they are motivated and interested in the course. This also confirms the expectation that students learn more in environments where instructional methods are congruent with their preferences (Young, Klemz and Murphy, 2003). Hence, instructional methods used by teachers must be effective, useful, satisfactory and good. Teachers need to motivate their students in order to obtain better results.

Course organization has the largest impact on Pedagogical Affect, being twice as important as Student-Instructor Interaction and Learning Performance. An organized course contributes to a more positive evaluation of students regarding teachers and their instructional methods. Since Student-Instructor Interaction is also positively associated with Pedagogical Affect, this suggests that students-teacher relationship has a major importance in the evaluation that learners make about teachers and their instructional methods. If students have a strong and open relationship with instructors, they will invest more in the learning process and create a more positive opinion about teachers and their methods. The relationship between Learning Performance and Pedagogical Affect confirms that students benefit from and enjoy more learning processes that have a strong interaction (Paswan and Young, 2002). 
Responsiveness is the major determinant of Student Interest, which is four times more important than Learning Performance. This finding reveals the importance of the human factor, confirming that although students might give importance to the learned outcome, when students perceive that teachers are investing and giving attention to them they react very positively and become much more interested (Paswan and Young, 2002).

Finally, there is a strong relationship between liking/concern and learning performance. Students evaluate themselves, teachers and their overall learning process through the analysis of their learning performance. Overall, students value instructors while taking into account their personal attractiveness and teaching qualities (Clayson and Haley, 1990).

\section{CONCLUSION}

Valuable information for teachers and school managers can be retrieved from our findings. Students appreciate interactive and student-focused methods (Honey and Mumford, 1992), considering the importance of student interest, instructional methods and organization. But at the same time, perceived learning is strongly influenced by instructors' personal qualities and teaching characteristics - responsiveness, liking/concern and instructional methods. The factors reported in this study try to capture the essence of good teaching. First, instructors are recommended to use instructional methods that involve students. Second, instructors must be agreeable and attentive, considering that students evaluate them as a person and as a teacher. Third, instructors must also be efficient in "delivering their service", because such responsiveness increases student interest. Finally, courses are encouraged to be well structured and organized, because course organization has a significant positive impact on perceived learning. 


\section{References}

1. Cahn S. Faculty members should be evaluated by their peers, not by their students. Chronicle of Higher Education 1987;Oct.(14):B2.

2. Clayson DE, Haley DA. Student evaluations in marketing: what is actually being measured? Journal of Marketing Education 1990;12(Fall):9-17.

3. Duke CR. Learning outcomes: comparing student perceptions of skill level and importance. Journal of Marketing Education 2002;24(3):203-217.

4. Dunn R, Giannitti MC, Murray JB, Rossi I. Grouping students for instruction: effects on learning style on achievement and attitudes. Journal of Social Psychology 1990;130(5):485-494.

5. Engelland BT, Workman L, Singh M. Ensuring service quality for campus career services centers: a modified SERVQUAL scale. Journal of Marketing Education 2000;22(3):236-245.

6. Feldman KA. Effective college teaching from the students' and faculty view: matched or mismatched priorities? Research in Higher Education 1998;28():291-344.

7. Fornell C, Larcker D. Evaluating structural equation models with unobservable variables and measurement error. Journal of Marketing Research 1981;18(1):39-50.

8. Frontczak NT. A paradigm for the selection, use and development of experiential learning activities in marketing education. Marketing Education Review 1998;8(3):25-34.

9. Gremler DD, McCollough MA. Student satisfaction guarantees: an empirical examination of attitudes, antecedents, and consequences. Journal of Marketing Education 2002;24(2):150-160.

10. Hammond LF, Snyder J. Authentic assessment of teaching in context. Teaching and Teacher Education 2000;16():523-545.

11. Honey P, Mumford A. The manual of learning styles. Berkshire: Maidenhead; 1992.

12. Hsu CHC. Learning styles of hospitality students: nature or nurture. Hospitality Management, 1999;18():17-30.

13. Karns GL. Marketing student perceptions of learning activities: structure, preferences, and effectiveness. Journal of Marketing Education 1993;15(1):3-10.

14. Marks RB. Determinants of student evaluations of global measures of instructor and course value. Journal of Marketing Education 2000;22(2):108-119.

15. Marsh H. Multidimensional students' evaluations of teaching effectiveness: a test of alternative higher-order structures. Applied Psychological Measurement 1991;83():285-296.

16. Marsh H. Students' evaluations of university teaching: dimensionality, reliability, validity, potential biases, and utility. Journal of Education Psychology 1987;11(3):707-794.

17. Marsh H, Cooper TL. Prior subject interest, students' evaluations, and instructional effectiveness. Multivariate Behavioral Research 1981;16():88-104.

18. Matthews DB. An investigation of students' learning styles in various disciplines in colleges and universities. Journal of Humanistic Education and Development 1994;33(3):65-74.

19. Parasuraman A, Zeithaml VA, Berry LL. A conceptual model of service quality and its implications for future research. Journal of Marketing 1985;49():41-50.

20. Paswan KA, Young JA. Student evaluation of instructor: a nomological investigation using structural equation modeling. Journal of Marketing Education 2002;24(3):193-202.

21. Richard D, Misra S, Auken SV. Relating pedagogical preferences of marketing seniors and alumni to attitudes toward the major. Journal of Marketing Education 2000;22(2):147-154. 
22. Silins H, Mulford B. Schools as learning organizations - Effects on teacher leadership and student outcomes. School Effectiveness and School Improvement 2004;15(3-4):443-466.

23. Tynjälä P. Towards expert knowledge? A comparison between a constructivist and a traditional learning environment in the university. International Journal of Education Research 1999;31():357-442.

24. Willemse M, Lunenberg M, Korthagen F. Values in education: a challenge for teacher educators. Teaching and Teacher Education 2005;21():205-217.

25. Young MR, Klemz BR, Murphy JW. Enhancing learning outcomes: the effects of instructional technology, learning styles, instructional methods, and student behavior. Journal of Marketing Education 2003;25(2):130-142. 
FIGURE 1

\section{CONCEPTUAL FRAMEWORK}

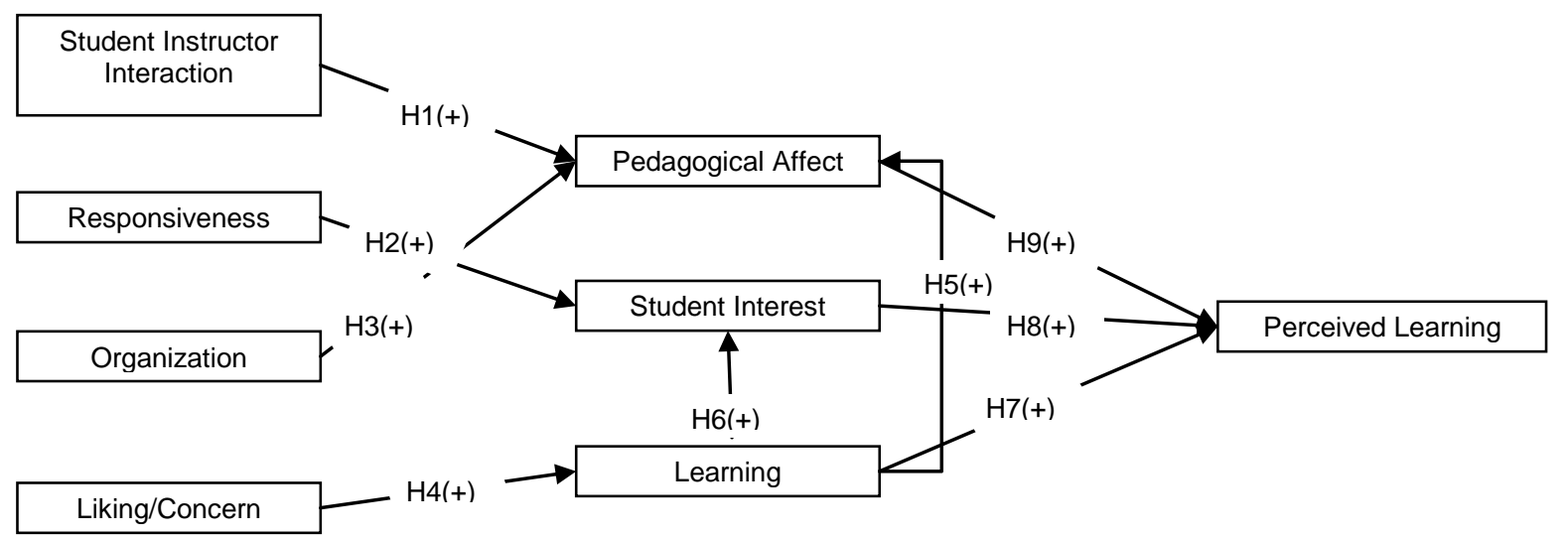

FIGURE 2

\section{SUMMARY OF SIGNIFICANT RELATIONSHIPS ${ }^{\text {a }}$}

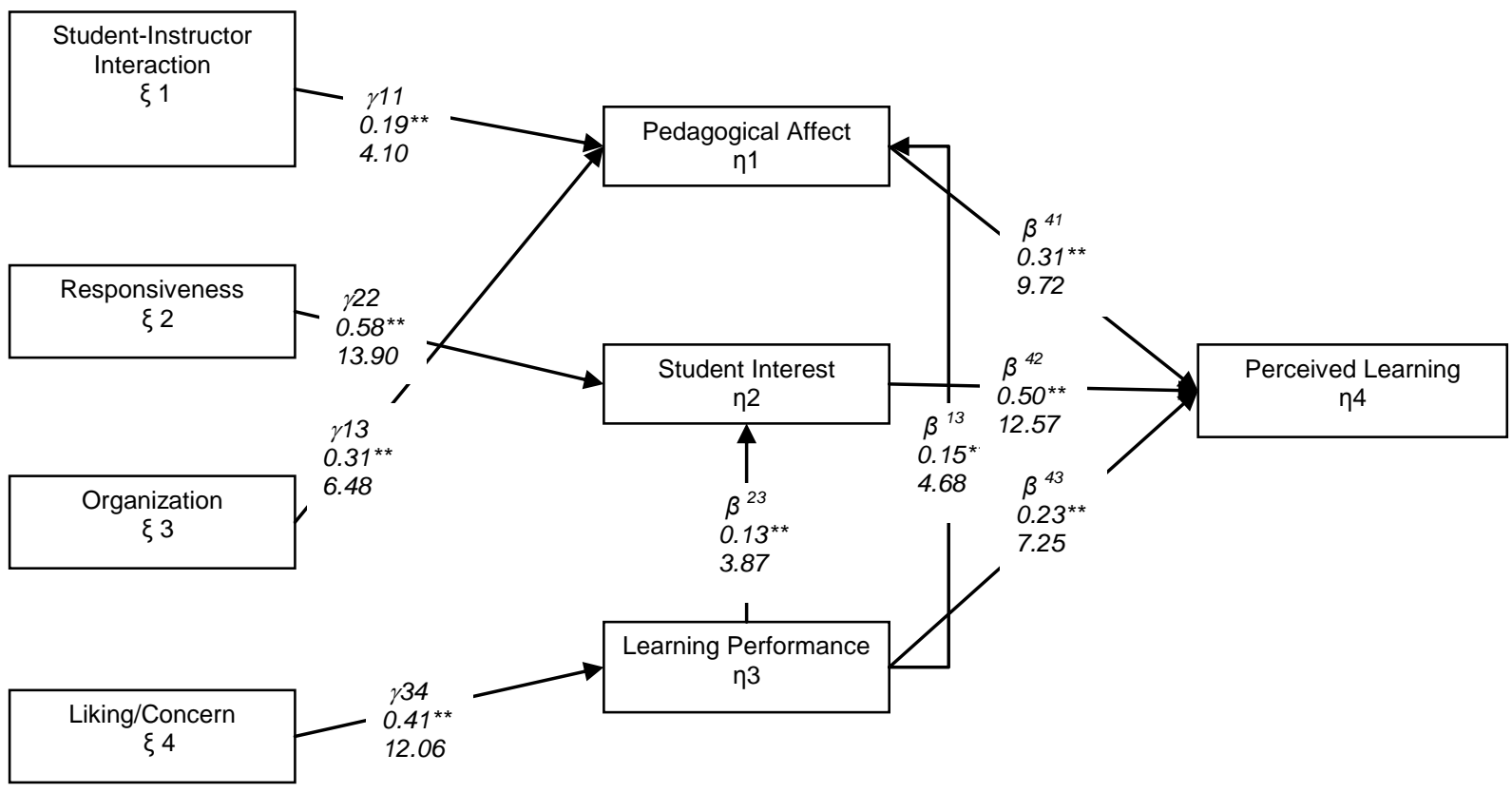

${ }^{a}$ Values in upper rows are completely standardized estimates. Values in lower rows are t-values. $* \mathrm{p}<0.05, * * \mathrm{p}<0.01$ (two-tailed test). 


\section{Appendix A: Constructs, scale items and reliabilities}

Student-Instructor Interaction ${ }^{1}\left(\alpha=.82, \rho_{\mathrm{vc}(\mathrm{n})}=.54, \rho=.83\right)$

(Scale $1=$ Strongly disagree $/ 5=$ Strongly agree)

V1 Instructor encouraged student to express opinion.

V2 Instructor is receptive to new ideas and others' views.

V3 Students had an opportunity to ask questions.

V4 Instructor generally stimulated class discussion.

${ }^{1}$ Source: Paswan and Young 2002

Responsiveness $^{2}\left(\alpha=.78, \rho_{\mathrm{vc}(\mathrm{n})}=.54, \rho=.77\right)$

(Scale $1=$ Strongly disagree $/ 5$ = Strongly agree)

V5 Tell students when they will be served

V6 Serve students promptly

V7 Always be eager to provide assistance

${ }^{2}$ Adapted from Engelland et al. 2000

Organization $^{3}\left(\alpha=.84, \rho_{\mathrm{vc}(\mathrm{n})}=0.64, \rho=0.84\right)$

(Scale $1=$ Strongly disagree $/ 5=$ Strongly agree)

V8 The course was well organized

V9 The material was presented in an orderly manner

V10 Instructor presents material in a clear and organized manner

${ }^{3}$ Source: Marks 2000; adapted from Paswan and Young 2002

Liking/Concern ${ }^{4}\left(\alpha=.84, \rho_{\mathrm{vc}(\mathrm{n})}=.63, \rho=.84\right)$

(Scale $1=$ Strongly disagree $/ 5=$ Strongly agree)

V11 I like the instructor as a person

V12 The instructor seems to have an equal concern for all students

V13 The instructor was actively helpful when students had difficulty

${ }^{4}$ Source: Marks 2000

Pedagogical Affect ${ }^{5}(\alpha=.90, \rho v c(n)=.70, \rho=.90)$

Overall, in this class the methods of instruction were...

V14 1-ineffective ... 7 - effective

V15 1-useless ... 7 - useful

V16 1- unsatisfactory ... 7 - satisfactory

V17 1-bad ... 7-good

${ }^{5}$ Adapted from Young, Klemz and Murphy 2003

Student Interest ${ }^{6}(\alpha=.76, \rho v c(n)=.44, \rho=.76)$

(Scale 1 = Strongly disagree $/ 5$ = Strongly agree)

V18 You were interested in learning course material.

V19 You were generally attentive in class.

19.52

V20 You felt the course challenged you intellectually.

V21 You have become more competent in this area.

${ }^{6}$ Adapted from Paswan and Young 2002

Learning Performance ${ }^{7}(\alpha=.87, \rho v c(n)=.58, \rho=.87)$

(Scale $1=$ Strongly disagree $/ 5=$ Strongly agree)

V22 The knowledge you gained.

V23 The skills you developed.

V24 Your ability to apply the material.

V25 Your desire to learn more about this subject.

V26 Your understanding of this subject.

${ }^{7}$ Adapted from Young, Klemz and Murphy 2003

Please evaluate this class regarding the following items:

Perceived Learning $\left.^{8}\left(\alpha=.79, \rho_{\mathrm{vc}(\mathrm{n})}=0.64, \rho=0.78\right)\right)$

(Scale 1 = Strongly disagree $/ 5=$ Strongly agree)

V27 I am learning a lot in this class

V28 As a result of taking this course, I have more positive feelings toward this

${ }^{8}$ Source: Marks 2000 
